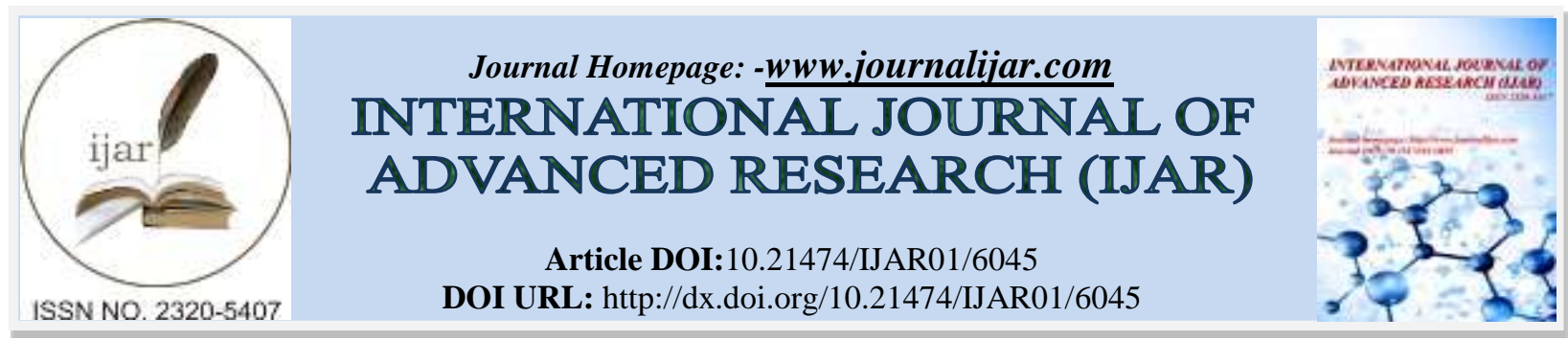

RESEARCH ARTICLE

\title{
EARLY MANAGEMENT OF SKELETAL CLASS III MALOCCLUSION WITH FACE MASK - A CASE REPORT.
}

\begin{abstract}
Dr. Abdul Baais Akhoon ${ }^{1}$ and Prof. Dr. Mohammad Mushtaq ${ }^{2}$.
1. PG student, Department of Orthodontics and Dentofacial Orthopaedics, Govt. Dental College, Srinagar.

2. Professor and Head, Department of Orthodontics, Govt. Dental College and Hospital, ShereenBagh, Srinagar, University of Kashmir.
\end{abstract}

\section{Manuscript Info}

Manuscript History

Received: 13 October 2017

Final Accepted: 15 November 2017

Published: December 2017

Key words:-

Developing class III Malocclusion,

Occlusal splint, Mixed Dentition.

\begin{abstract}
Class III malocclusion continues to be one of the most challenging problems confronting orthodontist and paediatric dentists owing to its unpredictable and unfavourable growth pattern. Although early orthopaedic intervention is recommended but still it is not customarily used because of poor patient compliance and convoluted appliance therapy. The following case report describes management of an 8-year old male patient in mixed dentition with developing class III malocclusion by modified occlusal splint along with facemask. Improved patient compliance with this new appliance enabled correction of malocclusion in 9 months and encouraging favourable skeletal growth for future.
\end{abstract}

Copy Right, IJAR, 2017,. All rights reserved.

\section{Introduction:-}

Class III malocclusion constitutes a very small proportion of malocclusion with its prevalence varying from 0.3 $3.5 \%$ among Indian children of 8-15 years of age (Kharbanda, 1993 and Kharbanda, 1991) ${ }^{5,6}$. Individuals with class III malocclusion either present with discrepancies limited to dentoalveolar component or may appear along with skeletal component as well. Hereditary along with environmental factors play a significant role determining extent of severity of the malocclusion (Litton, 1970) ${ }^{8}$. The characteristic features are seen at an early age usually between 3-5 years of age and instead of getting self corrected, its severity worsens with age. Conspicuous dental and skeletal features resulting in unpleasant aesthetics for the child and thus lead the parents to seek orthodontic treatment at an early age. Early orthopaedic treatment of class III in deciduous and early mixed dentition has been advocated with the goal of providing a favourable environment for normal growth and improving psychological development of the child. Correction utilising facemask or reverse headgear for maxillary deficiency and chin cap for Mandibular prognathism are well documented (Guyer, 1986) ${ }^{2}$. Even though recommended yet the concept of early intervention in class III malocclusion is not fully embraced because of its dependency on parent and children's compliance along with cumbersome appliance design (Joondeph 1993) ${ }^{3}$. Klemper reported application of Tandem appliance in early treatment (Klemper, 2003) ${ }^{7}$. However, literature still lacks report of management of class III malocclusion in deciduous dentition. This case report describes the management of 8 year old male child with class III malocclusion in mixed dentition stage using modified occlusal splint and facemask.

\section{Case Report:-}

An 8 year old growing male patient reported to the Orthodontic Department with chief complaint of lower front teeth overlapping the upper teeth. Family history was not contributory. Intra-oral examination showed that patient 
was in mixed dentition stage with mesial step occlusal relation, anterior edge to edge bite with no deviation of centric occlusion to centric relation and slight posterior cross bite (Fig.1). Extra-oral examination revealed mesoprosopic face with mild concave profile and slightly deficient maxilla (Fig.2.) The panoramic radiograph showed no missing teeth or pathologies. On analysing Lateral cephalogram patient had class III maxillomandibular relationship (ANB: -1 degree). There was horizontal growth tendency with FMA=22 degree (Fig.3). After thorough clinical examination, model and cephalometric analysis it was concluded that the patient is a case of developing class III malocclusion with anterior crossbite and deficient maxilla.

Hence, the treatment objective was protraction of maxilla to attain a positive overjet. Keeping in mind the objectives and limiting factors of earlier reported cases, correction with occlusal splint appliance with face mask was planned. Maxillary and mandibular impressions and bite registration was recorded. Maxillary splint component was designed with $0.9 \mathrm{~mm}$ stainless steel wire extending around maxillary arch from canine to canine and hooks were placed superiorly in canine region as per patient convenience. The acrylic component approximately $2-3 \mathrm{~mm}$ covering the occlusal aspect from canine to second molar on each side and extending buccally and palatally with $1 \mathrm{~mm}$ gingival clearance. Occlusal covering aided in disengaging the jaws and protraction. After verifying the fit of appliance, it was polished and cemented using glass ionomer luting cement. Face mask was adjusted aligning with commissure of lips for elastic traction at $15^{\circ}$ below occlusal plane to minimise counter clockwise rotation tendency.

Patient was instructed to wear the face mask initially 6-8 hours a day, gradually increasing the duration of wear to 12-14 hours per day in a span of 4 weeks to deliver approximately 300-500 g/side of force through elastics (Fig. 4). Patient was recalled after 24 hours to evaluate the appliance and check the compliance.
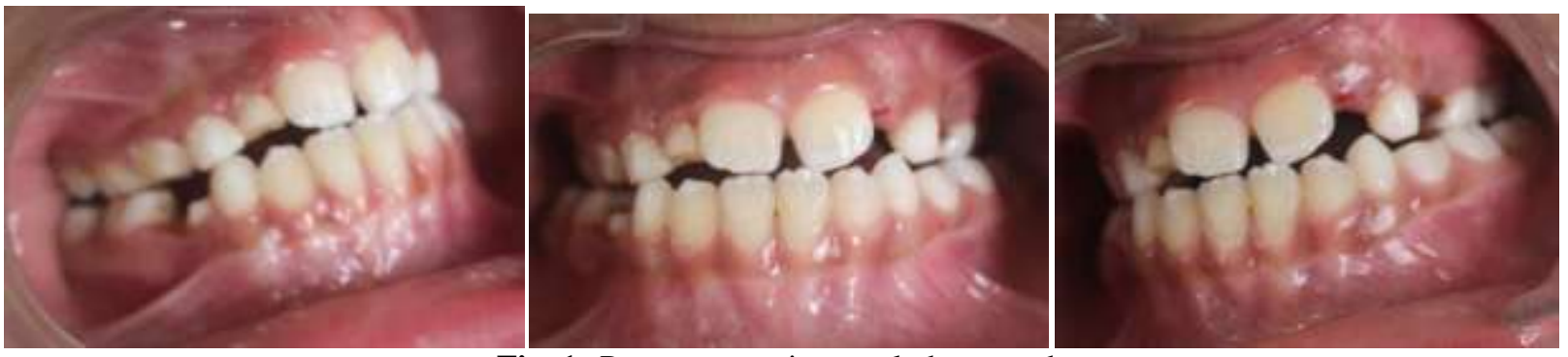

Fig. 1:-Pre treatment intraoral photographs
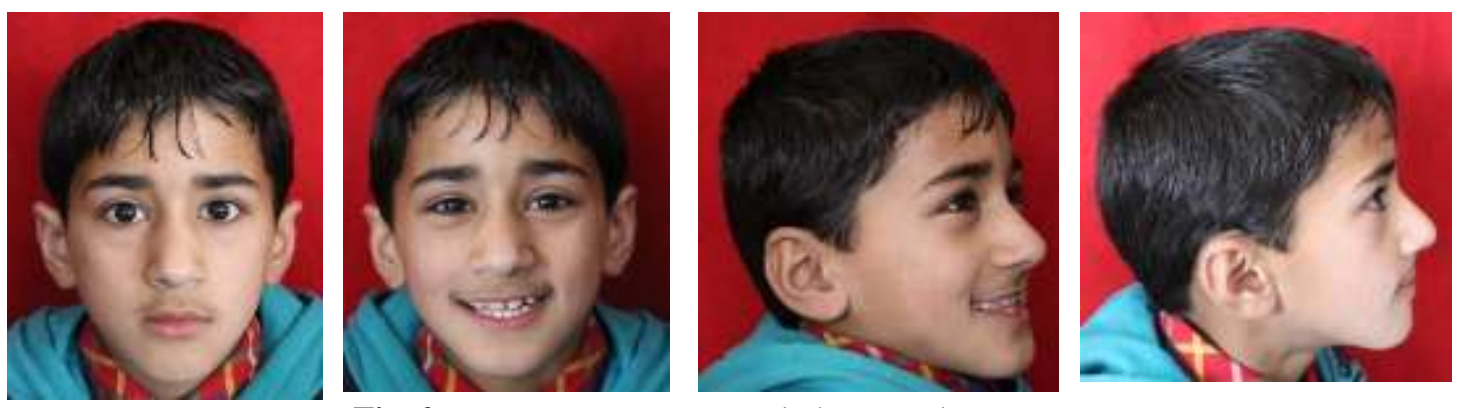

Fig. 2:-Pre treatment extra-oral photographs
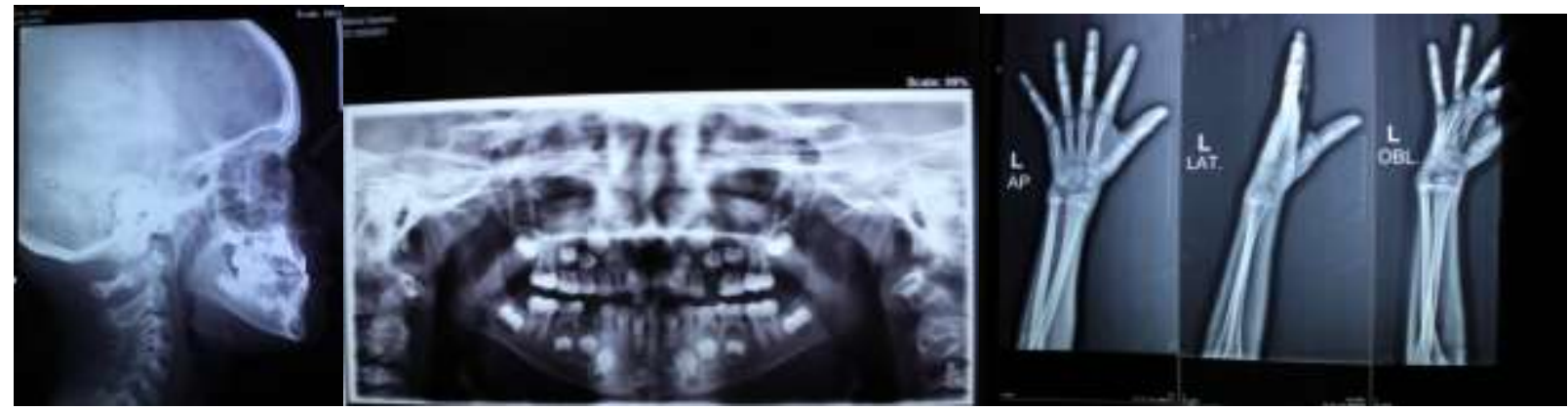

Fig. 3:-Pre treatment lateral cephalogram, orthopantomogram and hand wrist radiograph 

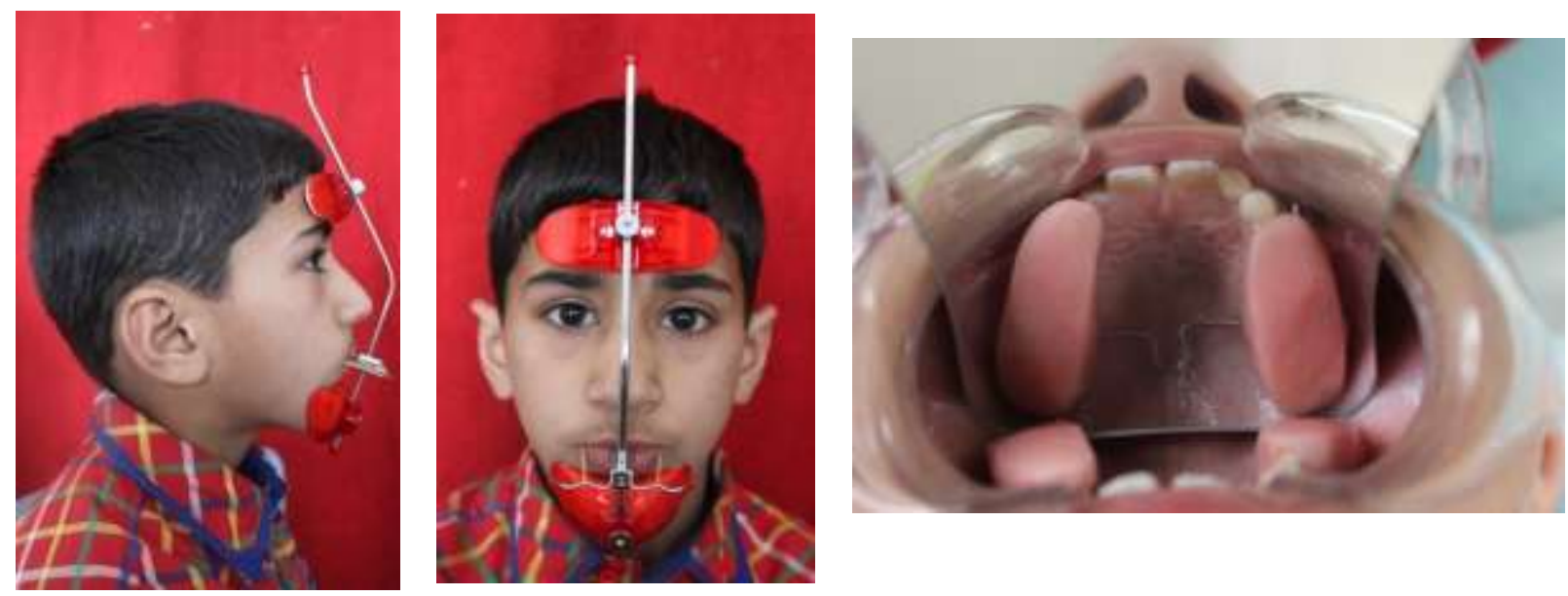

Fig. 4:-Appliance Design and Delivery

Oral hygiene instructions for maintenance was explained. At the end of 6 months, anterior cross bite was fully corrected with positive overjet of $2 \mathrm{~mm}$. After 9 months, cemented appliance was removed. Oral prophylaxis was done and carious teeth were aesthetically restored. Patient was followed up for 2 years with no report of relapse. Patient and parents were satisfied with the outcome of treatment (Fig. 5, 6 and 7).
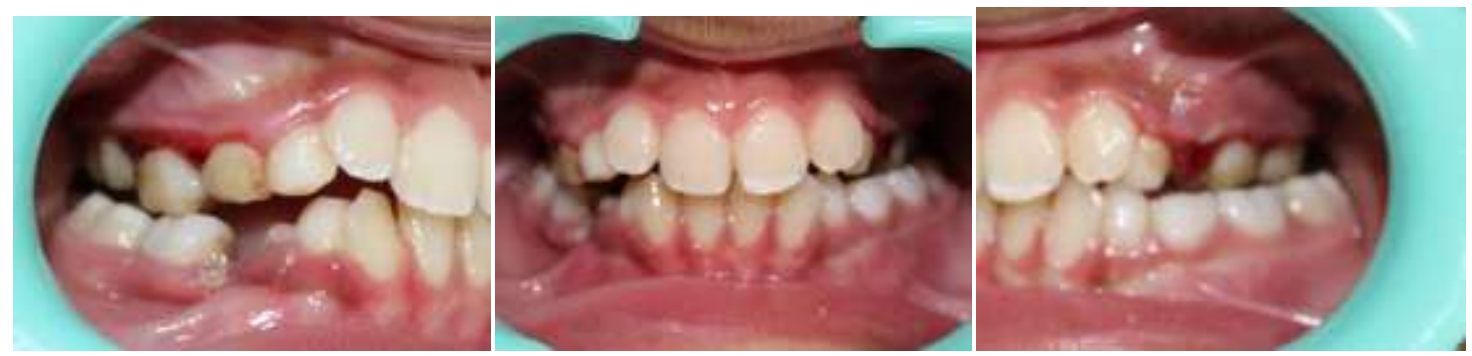

Fig. 5:-Post treatment intra oral photographs
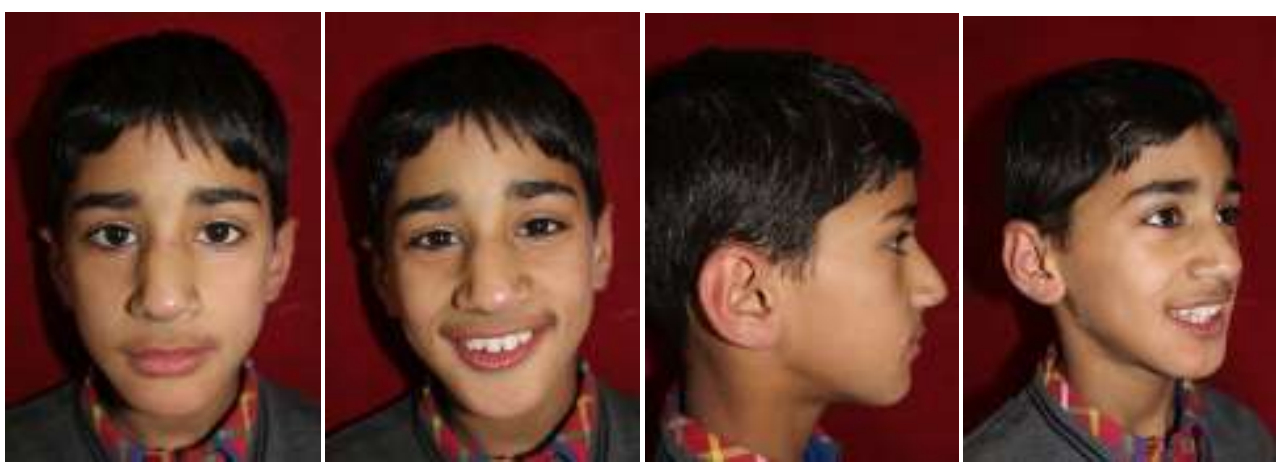

Fig. 6:-Post treatment extra oral photographs 


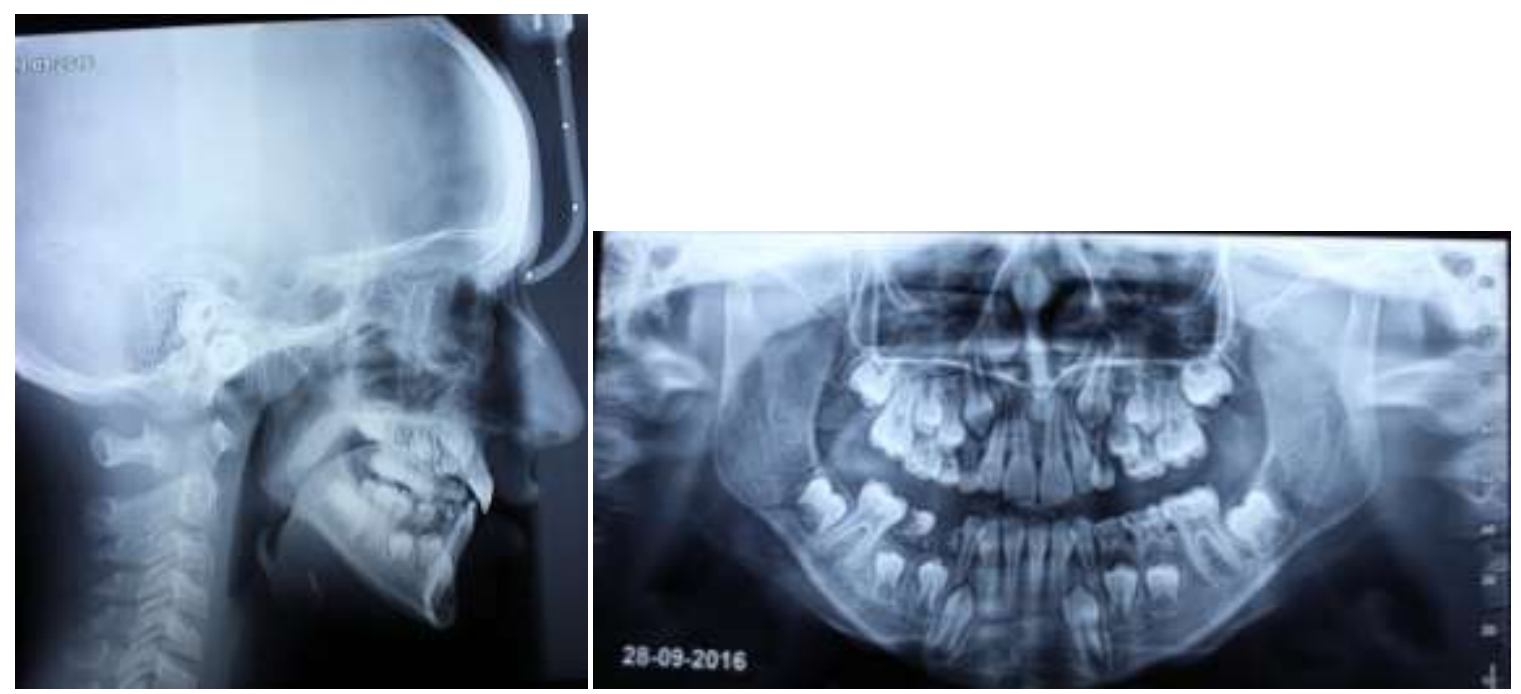

Fig. 7:-Post treatment lateral cephalogram and orthopantomogram

\section{Discussion:-}

Early recognition of characteristics predisposing to developing malocclusion in permanent dentition remains the mainstay in interceptive and preventive orthodontics. Fabled behaviour of developing class III malocclusion has remained immutable challenge. This malocclusion encompasses varying intensity of skeletal, functional and dental discrepancies (Paula Vanessa PedronOltramari-Navarro, 2013) ${ }^{11}$. For a long time, Mandibular prognathism was considered as major culprit. As Mandibular growth is essentially controlled by genetic factors, the choice of treatment was to wait until the growth is complete. Also, according to Guyer et al, 57\% of class III patients with either normal or prognathic mandible showed deficiency in the maxilla (Guyer, 1986) ${ }^{2}$. Thus, the developing class III malocclusion could be attributed to maxillary skeletal retrusion, mandibular protrusion or combination of both.

Additionally maxillary deficiency has now been regarded as important decisive factor in treatment planning and prognosis (Paula Vanessa PedronOltramari-Navarro, 2013) ${ }^{11}$. Variegated authors recommend that best time for intervention is the ending of primary dentition or early mixed dentition to provide favourable environment for craniofacial growth. Also, unrestricted growth of maxilla guides the mandible to its normal retrusive position (Almeida, 2011) ${ }^{1}$. Raising concerns and continued exploration have led clinicians to intervene at the earliest with one reported case of early management using reverse twin block (Sargod, 2013) ${ }^{13}$. Anchorage on deciduous teeth has been advocated instead of newly erupted permanent teeth anticipating external root resorption due to orthopaedic forces, enamel demineralization and loss of periodontal attachment (Marco Rosa, 2013) ${ }^{9}$.

This notable case presents earliest intervention in 8 year old male patient with class III malocclusion with modified occlusal splint and facemask. Family history ruled out genetic predisposition. Detailed examination and analysis, established the case to be of developing class III malocclusion with retruded maxilla (reverse overjet $=1 \mathrm{~mm}$, ANB = $-1^{\circ}$ ). Very mild posterior crossbite ruled out need for maxillary expansion. Taking into consideration the difficulties encountered due to complicated appliance design and lacunae of previous reported cases, treatment was focused on correction of class III malocclusion with maxillary protraction using occlusal splint with facemask. McNamara has described use of cemented occlusal splint with rapid maxillary expansion (RME) in young patients (McNamara, $1987)^{10}$. Protocol followed for protraction varies with researchers ranging from 500-2000 gms (Renato Rodrigues de Almeida, 2015) ${ }^{12}$.

The regimen used here is in accordance with the previous reported cases i.e. 300-600 gms per side with elastic

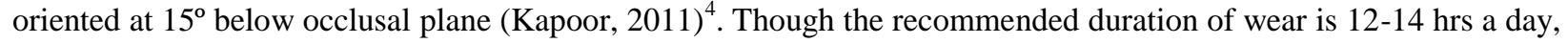
it was adjusted owing to his young age. So, patient was initially instructed to wear 6-8 hrs/day, gradually increasing to 12-14 hrs/ day over a span of 4 weeks. Appreciative patient friendly appliance design in adjunct to patient cooperation resulted in correction within 6 months.

However, patient was followed up for 2 years and there was no relapse. Evidence to date reports of just two cases of class III correction in deciduous dentition with reverse twin block and another using RME and facemask (Marco 
Rosa, 2013 and McNamara, 1987) ${ }^{9,10}$. Therefore, the present case report will be a valuable addition to the literature with patient and clinician friendly appliance. However, prospective long term evaluation is needed to assess coherence of this appliance.

\section{Acknowledgement:-}

The author wishes to acknowledge Professor Dr. Mohammad Mushtaq, Head of the Dept. of Orthodontics, Govt. Dental College, Srinagar for his guidance.

\section{References:-}

1. Almeida, M.R., Almeida, R.R., Oltramari-Navarro, P.V., Conti A.C., Navarro, R.L., Camacho, J.G. 2011. Early treatment of class III malocclusion: 10 year clinical follow up. J ApplOral Sci., 19(4): 43-439.

2. Guyer, E.C., Ellis, E.E., McNamara, Behrents R.G. 1986. Components of class III malocclusion in Juvenile and Adolescents. Angle Orthod.,56:7-30.

3. Joondeph, D.R. 1993. Early Orthodontic treatment. Am J OrthodentofacialOrthop, 104:199-200.

4. Kapoor, P., Kharbanda, O.P. 2011. Correction of skeletal class III in growing male patient by reverse pull facemask. JIndian SocPedodPrev Dent., 29:273-7.

5. Kharbanda, O.P., Sidhu, S.S. 1993. Prevalence studies on malocclusion in India-Retrospect and prospect. TheJournal of Indian Orthodontic Society.,24:115-118.

6. Kharbanda, O.P., Sidhu, S.S., Sundaram, K.R., Shukla, D.K. 1991. Occlusion status during early mixed dentition in Delhi Children. Project Report .Indian Council of MedicalResearch.

7. Klemper, L.S. 2003. Early Orthopedic class III treatment with modified Tandem appliance. J ClinOrthod, 37:218-23.

8. Litton, S.F., Ackermann, L.V., Isaacson, R.J., Shapiro, B.L. 1970. A genetic study of class 3 malocclusion. Am JOrtho.,58:565-77.

9. Marco Rosa, Alberto Caprigalio and PatriziaLucchi. 2013. Early treatment of class III malocclusion by rapid maxillary expansion and face mask therapy with deciduous dentition anchorage. SocietaItaliana Di Ortodonzia., 21-30.

10. McNamara, J.A. Jr. 1987. An orthopaedic approach to treatment of class III malocclusion in young patients. $J$ ClinOrtho, 21:598-608.

11. Paula Vanessa PedronOltramari-Navarro, Renato Rodrigues de Almeida, Ana Cláudia de Castro Ferreira Conti, Ricardo de Lima Navarro, Marcio Rodrigues de Almeida, LeandraSant Anna Ferreira ParronFernandes. Early treatment for class III malocclusion. Brazilian Dental Journal, 2013;24 (2): 167-173.

12. Renato Rodrigues de Almeida, Luiz Eduardo Alessio Junior, Renata Rodrigues de Almeida-Pedrin, Marcio Rodrigues de Almeida, ArnaldoPinzan, LuizSérgio Vieira. 2015. Management of class III malocclusion treated with maxillary expansion, facemask therapy and corrective orthodontics- a 15 year follow up. J Appl Oral Sci., 23(1):101-9.

13. Sargod, S.S., Shetty, N., Shabbir, A. 2013. Early class III management in deciduous dentition using reverse twin block. J Indian SocPedodPrev Dent., 31:56-60. 